deer, the Chinese have an extraordinary dislike for their fiesh. They are therefore only killed for the European markets, and sold at a low price. The venison is coarse and without much taste, but is considered tolerable for want of better; it is the only venison procurable in Shanghai. The animal itself gives sport to the gunner; and numbers are slaughtered every winter by the European followers of Nimrod in the name of sport. Their numbers however do not appear to get much thinned."

Another most remarkable characteristic of these antler- less deer is their extraordinary fecundity. Mr. Swinhoe states that according to the testimony of the natives the mothers have four or five young at a birth, and that this is corroborated by Europeans who have killed gravid females and found the like number of embryos in the uterus. This account is to some extent confirmed by observations on the Water-deer in captivity in Europe. Although the Zoological Society have not succeeded in inducing this animal to breed in the Regent's Park, this feat has been accomplished by M. Josephe Cornelly of the

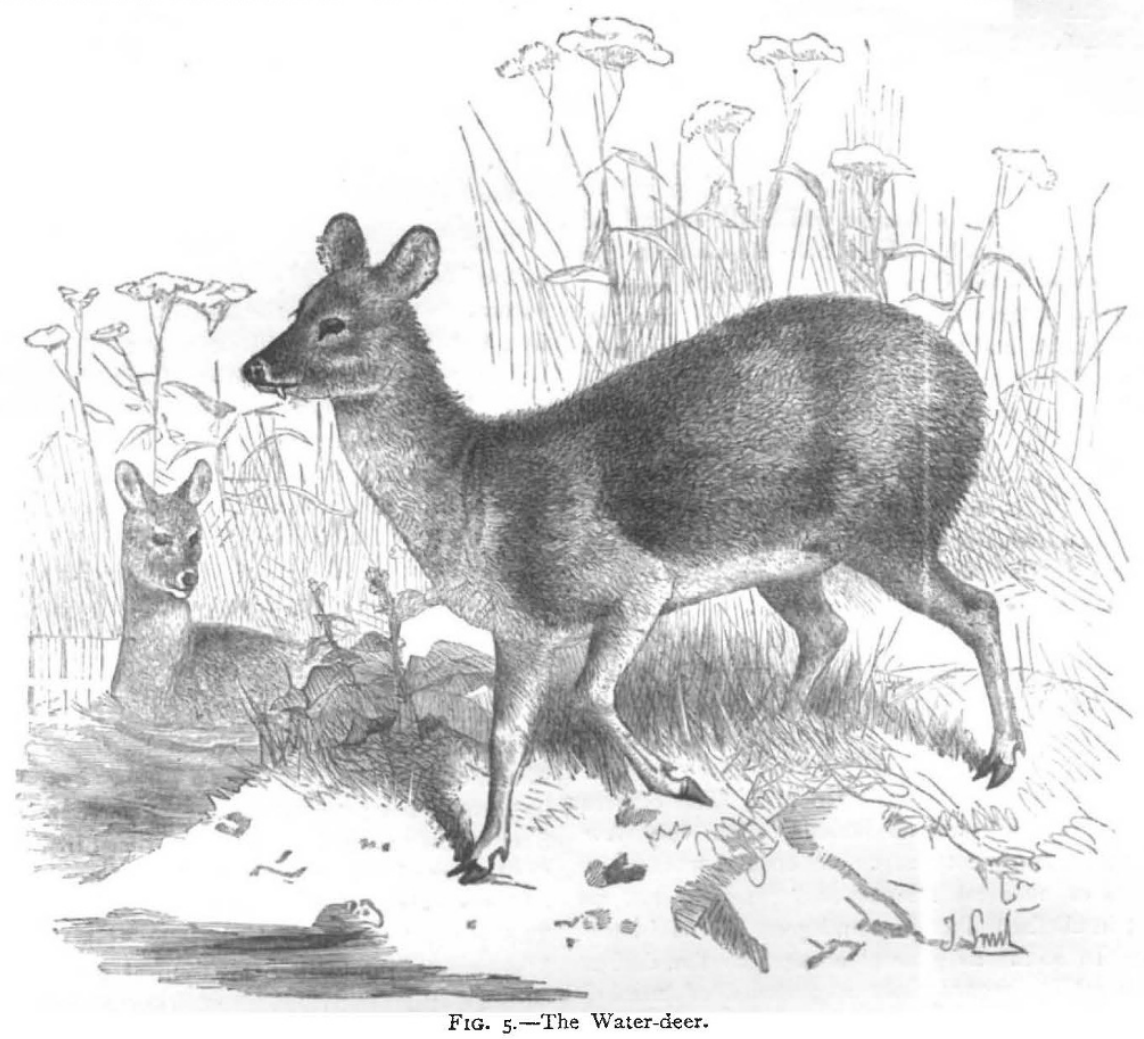

Château Beaujardin, near Tours, in France-one of the a height of about twenty inches, and is generally of a pale most successful "acclimatisers" in Europe. In M. fawn-colour, paler below.

Cornély's beautiful park one of these deer produced three young ones in the spring of 1879 , two of which, it is believed, lived to attain maturity. There can be no doubt therefore that the Water-deer is much more fruitful than the rest of its congeners, which certainly never produce more than two at a birth, and for this reason at least would be a valuable animal for domestication.

According to Mr. Swinhoe the "Chinese at Shanghai call this animal the $K e$; but at Chinkiang it is named Chang -the classical term for the Muntjac (Cervulus Reevesi). The Chinese dictionary, compiled under authority of the Emperor Kanghe, descrikes the $K e$ as 'stag-like, with feet resembling those of a dog, has a long tusk on each side of the mouth, and is fond of fighting.",

\section{NOTES ON THE GEOLOGY OF THE COREAN ARCHIPELAGO}

THIS archipelago, which consists of a number of I smaller groups of islands separated by a depth of water varying from twenty to fifty fathoms, lies off the south-west coast of the peninsula of Corea. . Whilst many of the larger islands vary from two to six miles in their extreme length, they are all of considerable height : their highest summits attain an elevation generally ranging between 600 and 1000 feet above the sea-Ross or Alceste Island, in the south-west corner of the archipelago, reaching to a height of as much as 1935 feet. The large and naked masses of rock which crown their summits give to these islands a somewhat rugged and ${ }^{x}$ Made during a brief visit of H.M.S. Hornet to these islands in October, 1878 . uninviting aspect; and their quaint inhabitants view with ill-concealed dislike the presence of foreign ships within their waters.

I was enabled to land on two occasions on the Island of Mackau - the largest of a group of islands bearing that name. About six miles in length, it possesses some halfdozen lofty peaks, which range in height from 800 or 900 feet to 1400 feet above the sea. Naked masses of quartzite or quartz-rock crown the summits and often compose the upper third of the hills, whilst a thick and dense growth of creepers, shrubs, and mimosas clothes the hill-slopes for their lower two-thirds. The quartzite passes insensibly into a compact quartzitic sandstone underlying it; and lower down this rock assumes a coarse-grained texture, ccasionally containing pebbles of quartz embedded in it. From the nature of the ground it was difficult to find 
trustworthy signs of bedding in these rocks. Cropping out in the lower third of the hills - from the cliffs and the slopes immediately above them-are beds of a highly micaceous rock-greisen-and a gneissose rock sometimes approaching in its characters the typical gneiss; these beds are inclined at an angle of $15^{\circ}$ to the eastnorth-east. Veins of quartz are observed to traverse both these rocks, whilst occasionally a layer of quartzan inch in thickness - separates contiguous beds.

I had no opportunity of landing on any other islands of the archipelago, many of which in their general appearance resemble that of the Island of Mackau.

\section{H. B. GUPPY}

\section{NOTES}

THE International Medical Congress which it is proposed to hold in London in the beginning of August will be the seventh of its kind. The previous meetings have been held biennially in the principal university towns of the Continent. At the last meeting in Amsterdam in 1879 , a general wish was expressed that the next should be in England, and the wish having been informally communicated to the Presidents of the College of Physicians and the College of Surgeons, they called a meeting of presidents or other delegates of all the Univerities, Medical Corporations, Public Medical Services, and the Medical Societies. The proposal to hold the Congress in London was heartily agreed to, and an Executive Committee was appointed under whose direction, and, especially, by the energy of the General Secretary, Mr. MacCormack, a very large scheme has been arranged for the discussion of the most interesting questions in all the divisions of the Medical Sciences. The Meetings will be held in fifteen sections, in rooms of most of which the use has been granted by the University of London, the Royal Academy, and all the learned Societies at Burlington House. Others have been engaged at Willis's Rooms. The officers and councils of the several sections include, with very few exceptions, all the chief and most active teachers and workers in the several subjects of medical science and practice, not in London alone, but in all the universities and great towns in the United Kingdom. In so far as general consent to the design of the Congress may be regarded as a promise of success, all looks well, and the agreement of our own countrymen is well matched by the assurances of co-operation already received from a large number of the most distinguished medical investigators and practitioners in both the Old World and the New. About 4000 invitations were issued, and it is expected that the roll of members will include at least 2000 names. Of course there are large arrangements for receptions and various hospitalities, and for making London as agreeable and instructive as may be in August; but if the design in the programme of the Congress be fairly fulfilled, a great quantity of hard and useful scientific work will be well done.

AT a meeting of the American Academy of Arts and Sciences held in Boston, Massachusetts, on January 12, the Rumford medal was conferred on Prof. Josiah Millard Gibbs, of Yale College, for his researches on Thermodynamics.

WE regret to hear of the death of Prof. James Tennant, F.G.S., the well-known mineralogist. Mr. Tennant was the assistant and afterwards the successor of Mr. Mawe, anthor of "Travels in Brazil," and of a "Treatise on Diamonds," and by adding to the series obtained by Mr. Mawe many fine specimens from every part of the globe, succeeded in thus forming a very large and valuable collection of minerals. Mr. Tennant was an excellent authority on gems, and his advice was taken by the Government with respect to the cutting of the Koh-i-Noor and other crown jewels. Besides holding the office of "Mineralogist to the Queen," Mr. Tennant was for many years Professor of
Geology and Mineralogy in King's College, London, and after he resigned the professorship of the former science, still retained the post of Professor of Mineralogy, which he held at the time of his death. Mr. Tennant, in conjunction with the late Prof. Ansted and the Rev. W. O. Mitchell, wrote the treatise ion Geology, Mineralogy, and Crystallography for Orr's "Circle of the Sciences," and he was also the author of some smaller educational works. Mr. Tennant did much useful work in preparing collections of minerals and fossils suitable for educational purposes; and by popular lectures and in other ways he aided in disseminating a knowledge of those sciences in which he was so greatly interested. Mr. Tennant had reached the age of seventy-three at the time of his death.

Prof. Martin Duncan, F.R.S., has been elected president of the Royal Microscopical Society.

THE Daily Newes Naples correspondent writes with reference to the Zoological Station at Naples that the average number of naturalists working in the laboratory was formerly about twentyfive, but this year it will be above thirty, adding to which the permanent staff of the station, there are altogether nearly forty naturalists bent upon promoting original research into marine zoology and botany, while enjoying the most unusual facilities and elaborate technical arrangements that have ever yet been contrived. The use of the diving apparatus has enabled the naturalists to find marine plants hidden in cracks and crevices and on the undersides of overhanging rocks, which otherwise would never have been brought to light, for the ground-net cannot reach them. By this means many interesting botanical problems have been brought nearer to a solution.

Colonel PRejewalski has just returned to St. Petersburg with a fine botanical collection he has made in Kansu. Dr. Maximowicz states that upon a cursory examination his previous impression is strengthened that we have to do here not with the flora of China, but with an altogether different one, belonging to the border of the great Central Asiatic plateau. There are no Chinese forms of trees or shrubs whatever, not even an Acer. The general character is entirely high alpine and cold. Dr. Maximowicz thinks that this Central Asiatic plateau has a flora with a distinct individuality of its own, and proposes to call it the Tangut flora, from the name applied by its first European explorer, Marco Polo, to the people inhabiting this inclement and inaccessible region.

THE arrangements for the international medical and sanitary exhibition of the Parkes Museum of Hygiene, which is to be held at South Kensington from July 16 to August I3, are now complete. The exhibition is to comprise everything that is of service for the prevention, detection, cure, and alleviation of disease.

The Clarendon Press is about to issue a new edition of the Iate Admiral W. H. Smythe's "Cycle of Celestial Objects," a book which by universal consent has done more to promote popular astronomy in England than any other work of the kind. The new edition has been edited by Mr. G. F. Chambers, F.R.A.S., whose "Handbook of Astronomy," another Clarendon Press book, is well known. This volume, though professedly only a new edition, may be regarded as almost a new work. Whereas the original edition comprised only 850 objects, the new one comprises no fewer than 1604 . But it is not merely in the number of the objects dealt with that the usefulness of the new edition will consist. It will be found that $\mathrm{Mr}$. Chambers has cut down here, expanded there, and revised everywhere, Admiral Smythe's printed matter, so as to embody the progress of the science down to the year 1880 . What this means in the case of hundreds of double-stars annually undergoing re-measurement, and many of them annually undergoing change, can only be 